Гумерова А.C., Якубов Р.Н., Научно-производственный центр (Комплекс-Ойл», г. Уфа, Россия.

Ленченкова Л.Е., нефтяной технический университет,

Илаш Д.А. г. Уфра, Россия

\title{
РАЗРАБОТКА ПЕРСПЕКТИВНОГО ОРГАНО-ГИБРИДНОГО СОСТАВА НА ОСНОВЕ МОДИФИЦИРОВАННОГО ПОЛИАКРИЛОНИТРИЛА ПРИ ПРОВЕДЕНИИ РЕМОНТНО- ИЗОЛЯЦИОННЫХ РАБОТ В СКВАЖИНАХ
}

Введение:

Материалы и методы исследования:

В связи с вступлением большей части месторождений в завершающую стадию разработки возрастает актуальность вопросов, связанных с повышением эффективности проводимых на осложненном фонде скважин ремонтно-изоляционных работ (РИР). При обосновании технологий РИР преимущественно внимание сосредоточено на выборе химреагентов для установления изоляционных экранов в обводнившихся зонах пласта.

Получен новый органо-гибридный состав на основе полиакрилонитрила путем гидролиза силикатом натрия. Проведен комплекс реологических исследований для определения структурно-механических свойств композиции с соляной кислотой. Выполнены спектральные исследования для уточнения механизма гелеобразования новой органо-гибридной композиции.

Результаты исследований и их обсуждение:

Анализ результатов экспериментальных исследований нового состава на основе гидролизованного полиакрилонитрила позволил выявить синергетический эфффект, связанный с наличием вязко-пластичных и вязко-упругих свойств, обеспечивающих высокую эффективность его применения в пластовых условиях. Механизм гелеобразования новой композиции на основе реагента КОМ-С по-видимому происходит за счет образования полимерных нитей, армирующих силикатную составляющую, а образование силоксановых связей достигается посредством димеров, являющихся (мостиками) между глобулами.

Выводы:

Гидролизованный силикатом натрия полиакрилонитрил является перспективным реагентом для гелеобразующей композиции, способной при реакции с соляной кислотой образовывать прочный изоляционный экран в высокопроницаемых обводнившихся зонах пласта.

Ключевые слова:

ремонтно-изоляционные работы, силикат натрия, гидролизованный полиакрилонитрил, вязко-пластичные свойства, изоляционный экран, реологические характеристики, элементный состав. 
Gumerova A.S. Yakubov R.N. Lenchenkova L.E. Ilash D.A.

Scientific-Production Center «Complex-Oil», Ufa, Russia

\section{DEVELOPMENT OF PERSPECTIVE ORGANO-HYBRID COMPO- SITION BASED ON MODIFIED POLYACRYLONITRILE DURING REPAIR AND INSULATION OPERATIONS IN WELLS}

Introduction: Due to the entry of most of the fields into the final stage of development, the relevance of issues related to improving the efficiency of repair and insulation operations (RIO) conducted at the complicated well stock increases. In justifying RIO technologies, primarily focuses on the selection of chemical reagents for the insulating screens formation in the reservoir flooded zones.

Materials and methods: A new organo-hybrid composition based on polyacrylonitrile was obtained by hydrolysis with sodium silicate. A complex of rheological studies was carried out to determine the structural and mechanical properties of the composition with hydrochloric acid. Spectral studies were performed to clarify the mechanism of gel formation of a new organo-hybrid composition.

Results and discussion: Analysis of the new composition based on hydrolyzed polyacrylonitrile experimental studies results revealed a synergistic effect associated with the presence of both viscous-plastic and viscous-elastic properties, ensuring high efficiency of its application in reservoir conditions. The mechanism of gelation of the new composition based on the COM-C reagent apparently occurs due to the formation of polymer filaments reinforcing the silicate component and siloxane bonds formation is achieved by means of dimers, which are "bridges" between globules.

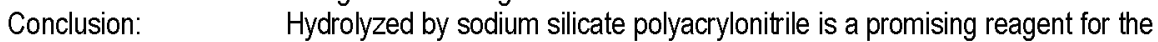
gel-forming composition, capable to form a durable insulating screen in highly permeable watered zones of the formation when reacting with hydrochloric acid.

Keywords: $\quad$ repair and insulation operations, sodium silicate, hydrolyzed polyacrylonitrile, viscoplastic properties, insulation screen, rheological characteristics, elemental composition.

\section{Введение}

Эффективность применяемых технологий проведения ремонтно-изоляционных работ определяется соответствием изолирующих составов условиям их применения и соблюдением технологии приготовления и закачки в пласт. В последние годы для указанных целей предложено и обосновано несколько сотен композиций. Несмотря на многообразие разработанных композиций, в промысловых условиях используются с той или иной успешностью не более десяти. Причина этого в том, что составы не технологичны и имеют ограничения по критериям применения, характеризуются низкой изоляционной стабильностью и т.д. Однако эффективность применения изоляционных материалов может быть заметно увеличена путем изменения их физико-химических и реологических свойств, в том числе путем создания новых полимерных составов, совмещающих одновременно вязко-упругие и вязко-пластичные свойства, предающие более высокие прочностные характеристики и устойчивость к преждевременному размыву пластовой водой [1]. 


\section{Материалы и методы исследования}

Новый акриловый реагент КОМ-С, полученный на основе гидролиза полиакрилонитрильного волокна (ПАН) силикатом натрия $(\mathrm{CH})$, может быть эффективным изоляционным составом [2-4]. В ходе термической реакции образуются сополимеры акриламида и акриловой кислоты, звенья имидокремнекислового эфира. Непосредственно схема гидролиза ПАН силикатом натрия представлена на рисунке 1 .

Начальная стадия рассматриваемого процесса включает образование сопряженных нафтиридиновых циклов в цепи полимера. Далее идет образование эфира (полилимида кремниевой кислоты) в результате присоединения анионов кремниевой кислоты, возникающих при гидролизе силиката натрия по нафтиридиновому циклу.

При гидролизе СН образуется гидроксид ион, который участвует в щелочном гидролизе полиакрилонитрила. Образованием натриевой соли полиакрилата или сополимера акрилата и акриламида завершается полный гидролиз.

Гидролиз под действием силиката натрия проходит при температуре выше $95{ }^{\circ} \mathrm{C}$ и при соотношении СН/ПАН $\geq 15: 1$, образующийся продукт однороден, в нем отсутствуют волокнистые включения. Для выявления компонентного состава полученного реагента был выполнен элементный анализ.

С целью изучения химического состава и свойств нового реагента были выполнены исследования спектров поглощения в ИК диапазоне.
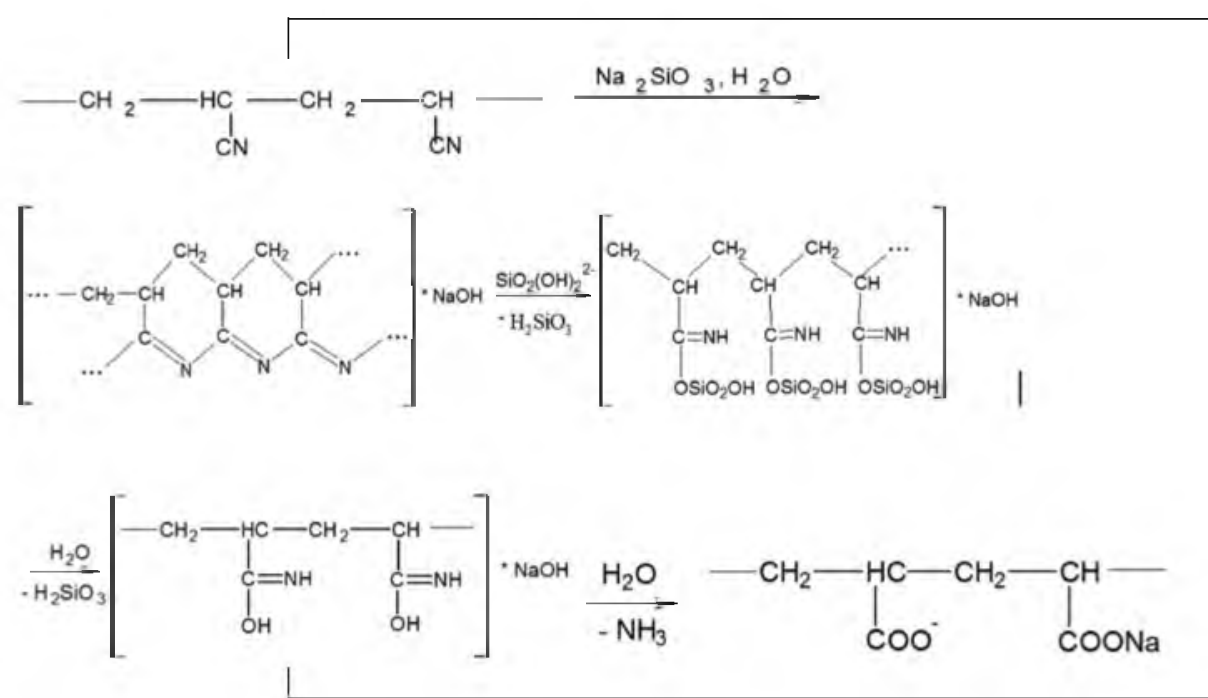

Рис. 1. 
Путем сопоставления ИК-спектров нового реагента со спектрами известных можно уточнить химические связи, характеризующиеся отдельными полосами поглощения электромагнитных волн ИК-диапазона. Диапазон волновых чисел установлен до $4000 \mathrm{~cm}^{-1}$, перекрывающий интервал интенсивного поглощения ИК-волн силикатными соединениями.

Для определения структурно-механических свойств полученной композиции был выполнен комплекс реологических исследований на модульном динамическом реометре HAAKE MARS III (Германия). Испытания проведены в режиме контролируемой скорости врашения ротора с применением измерительной системы плоскость-конус. В ходе исследований определялась кривая течения при условии пошагового изменения скорости вращения ротора.

Измерения определялись пошагово в момент выхода результируюшего напряжения сдвига $(\tau)$ на стационарное значение. Далее скорость вращения ротора увеличивали и фиксировали следующее значение напряжение сдвига. В исследуемом интервале 1-60 с. скорость сдвига линейно увеличивалась с интервалом в 1 секунду, определялись экспериментальные точки из экспериментальных данных, отбраковывались точки, которые явно противоречили физическому смыслу реологическим процессов и появившихся по видимому за счет погрешности прибора. Кривые течения снимались в широком диапазоне скоростей сдвига, то есть фиксировалась реакция образца на воздействие меняющихся сдвиговых напряжений. Как известно кривая течения является зависимостью напряжения сдвига от скорости сдвига. Непосредственно по линейным зависимостям $\tau=\mathrm{f}(\omega)$ рассчитываются значения вязкости ( $)$ для псевдопластичности и ньютоновских жидкостей.

В нефтепромысловой практике хорошо известна композиция на основе гипана, жидкого стекла (ГИЖ) и соляной кислоты $(\mathrm{HCl})$. Для выяснения приоритетов между составами на основе реагента КОМ-С и его прототипом были выполнены физико-химические исследования с массовыми соотношениями $\mathrm{CH} /$ гипан $1: 1$ или $2: 1$, а СН/HCl в интервале $0,5: 30$. Также были проведены исследования по определению содержания элементов в пересчете на оксиды новой композиции КОМ-С и композиции, используемой в качестве сравнительной базы ГИЖ методом рентгено-флуоресцентного анализа. В каждой из композиций определяли содержание кремния и других элементов в пересчете на оксиды. 


\section{Результаты исследований и их обсуждение}

Результаты элементного анализа нового синтезированного реагента КОМ-С представлены в таблице 1.

Таблица 1. ЭЛЕМЕНТНЫЙ АНАЛИЗ НОВОГО РЕАГЕНТА КОМ-С Table 1. Elemental analysis of the new reagent COM-C

\begin{tabular}{l|l|l}
\hline Содержание, \% масс \\
\hline $\mathrm{C}$ & $\mathrm{H}$ \\
\hline 12,96 & Зола \\
\hline 13,40 & 62,99 \\
\hline 2,95 & 63,19 \\
\hline
\end{tabular}

В синтезированном реагенте содержится некоторое количество силиката натрия, что подтверждается высоким содержанием в нем золы. Этот факт связан с тем, что в процессе гидролиза в ПАН образуются звенья имидокремнекислового эфира, часть из которых остается в сополимере и не подвержена последующему гидролизу.

Сопоставление ИК-спектров нового реагента и раствора $\mathrm{CH}$ показало, что в обоих спектрах обнаружена полоса поглощения в диапазоне 900 $1100 \mathrm{~cm}^{-1}$, характерная для колебаний группы $\mathrm{Si}-\mathrm{O}$, что и подтверждает силикатную составляющую в новом синтезированном реагенте. Причем в ИКспектре нового реагента отсутствует нитрильная группа, которая характерна на поглощение в диапазоне волновых чисел 2248-2253 $\mathrm{cm}^{-1}$. Кроме того, наблюдали интенсивное поглощение в области $1554 \mathrm{~cm}^{-1}$, связанное с возникновением СОО-групп, и поглощение в диапазоне $1650-1700 \mathrm{~cm}^{-1}$, связанное с наличием амидных групп.

Таким образом, при гидролизе ПАН силикатом натрия образуется новый армированный реагент сополимер акриламида и акриловой кислоты, содержащий небольшое количество звеньев имидоэфира кремниевой кислоты.

По результатам реологических исследований оптимальной композиции, состоящей из армированного силиката концентрации - $10 \%$ и соляной кислоты $-3 \%$, получены зависимости напряжения сдвига и кажущейся вязкости от скорости сдвига, представленные на рисунке 2.

Характер зависимостей свидетельствует о росте величины напряжения сдвига с момента приложения нагрузки, обусловленном процессом сопротивления структуры образца разрушению при условии увеличения нагрузки. Так, после достижения максимальной величины нагрузки происходит уменьшение напряжения сдвига, связанное с разрушением пространственной структуры геля. Кроме этого, происходит снижение значения кажущейся вяз- 


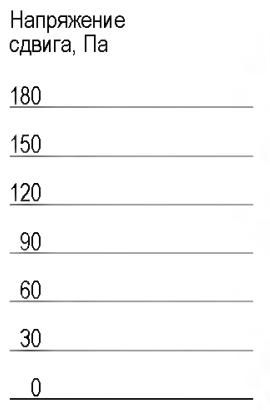

0

Кажүщаяся

вязКОсть, Па*

$\underline{150}$

120

90

60

30

0

Рис. 2.

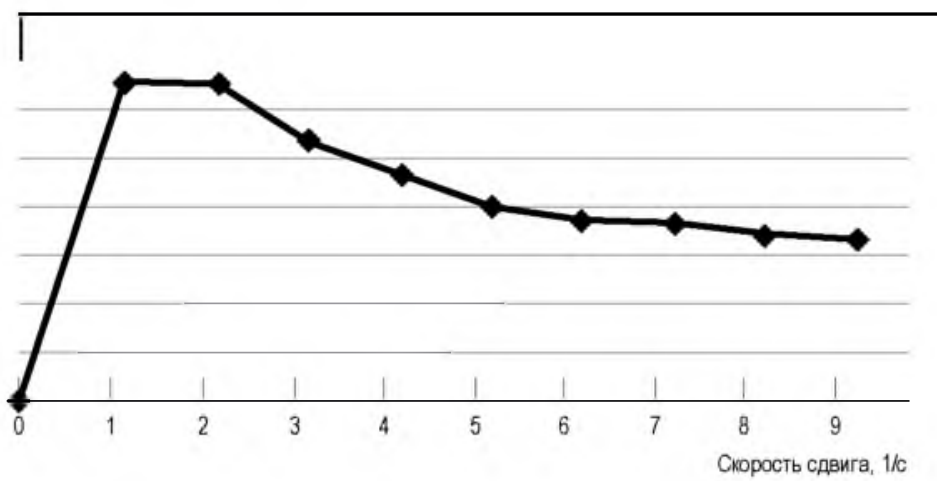

Скорость сдвига, $1 / \mathrm{c}$

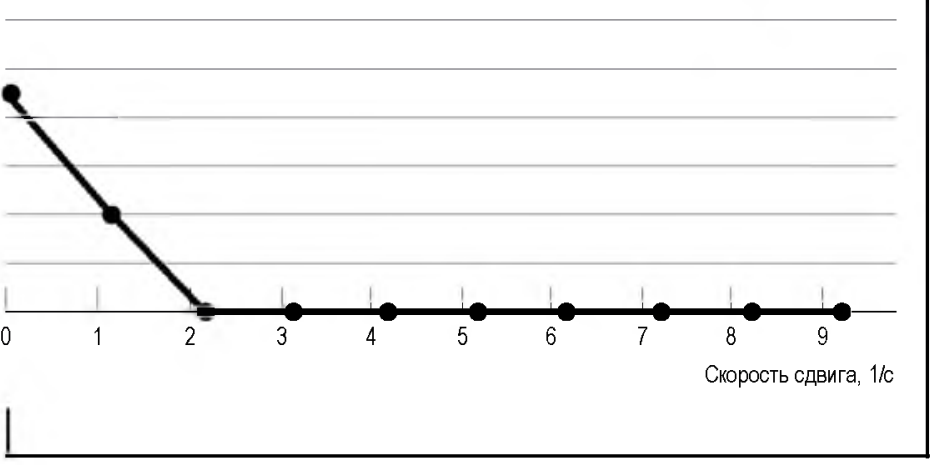

Зависимость напряжения сдвига и кажущейся вязкости от скорости сдвига при $20^{\circ} \mathrm{C}$.

Pic. 2. Shear stress and apparent viscosity as a function of shear rate at $20^{\circ} \mathrm{C}$.

кости до постоянного значения. Непосредственно прочность геля определяли по значению напряжения сдвига, соответствующему максимальному значению, т.е. моменту характеризующему процесс разрушения каркаса структуры геля [5,6].

Прочностные характеристики гелей определялись при температуре $20^{\circ} \mathrm{C}$ и $70{ }^{\circ} \mathrm{C}$. На рисунке 3 приведена зависимость напряжения сдвига от скорости сдвига при $70^{\circ} \mathrm{C}$ для сравнения с гелями при $20^{\circ} \mathrm{C}$.

В эксперименте с прототипом (смеси гипана и $\mathrm{CH}$ ) с массовыми соотношениями $\mathrm{CH} /$ гипан $1: 1$ или $2: 1$, а СН/ $\mathrm{HCl}$ в интервале $0,5: 30$ его разбавляли водой до получения растворов с вязкостью, соответствующей вязкости $10 \%$ раствора гипана. При соотношении СН/гипан $1: 1$ при разбавлении 76\% воды уже через 40 мин. образуется гель, при разбавлении $88 \%$ воды гель образуется через 9,3 часа.

Повышение температуры резко ускоряло процесс гелеобразования. Так, при $50{ }^{\circ} \mathrm{C}$ при двукратном разбавлении водой время гелеобразования со- 


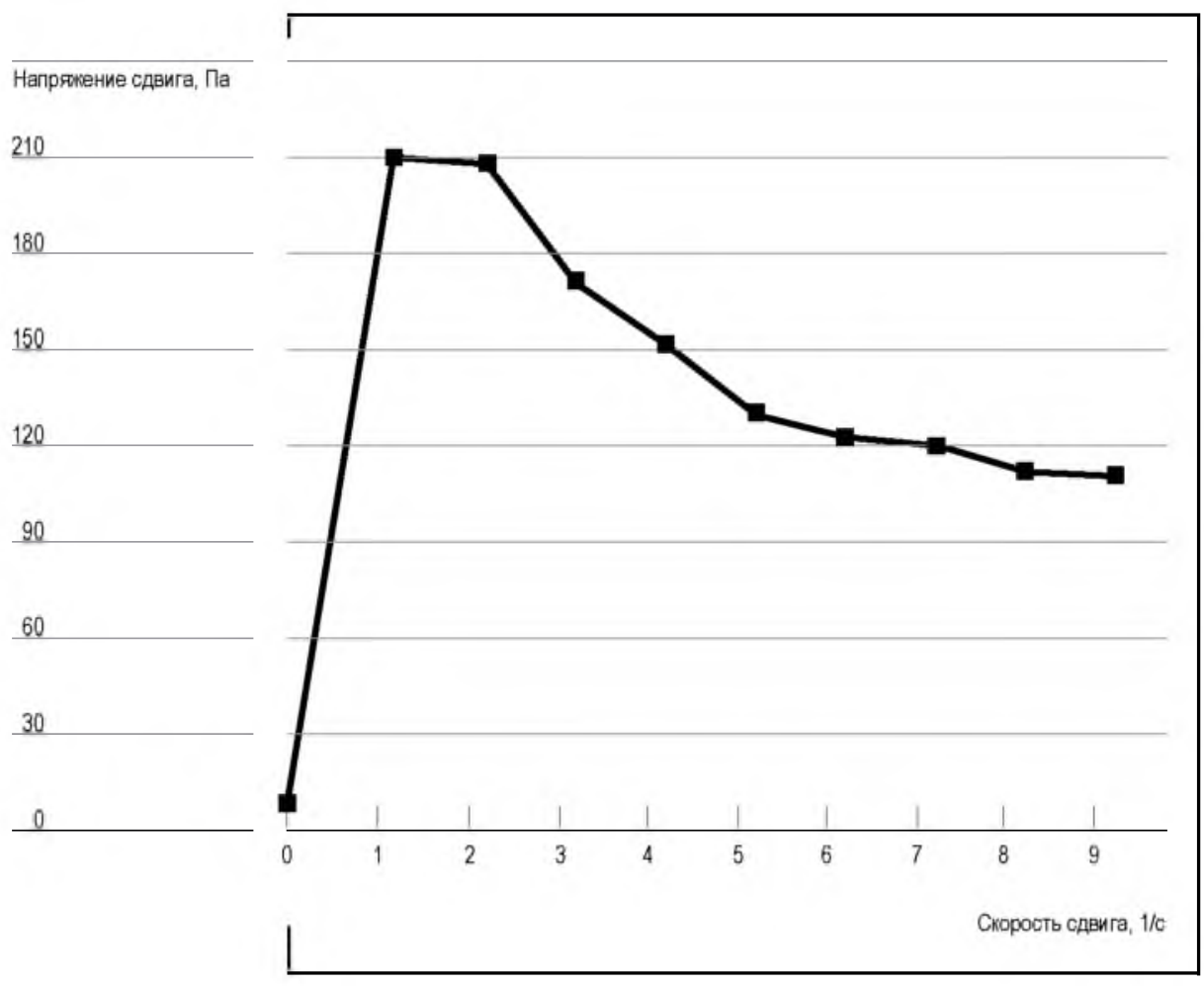

Pис. 3.

\section{Зависимость напряжения сдвига от скорости сдвига при} $70^{\circ} \mathrm{C}$.

Pic. 3. Shear stress as a function of shear rate at $70^{\circ} \mathrm{C}$.

ставило 1,3 часа. При увеличение температуры до $90{ }^{\circ} \mathrm{C}$ и разбавлении водой до $87 \%$ гелеобразование происходило через 10 мин.

Известно, что на время гелеобразования и прочностные характеристики геля заметное влияние оказывает концентрация исходных реагентов композиции. Так, на рисунке 4 представлена зависимость времени гелеобразования и прочности геля от конщентрации соляной кислоты при соблюдении условия неизменной концентрации реагента КОМ-С $-10 \%$ при $20^{\circ} \mathrm{C}$. Из данных, приведенных на графиках, следует, что при росте концентрации кислоты увеличивается прочность геля при уменьшении времени гелеобразования. При концентрации соляной кислоты в растворе более $5 \%$ масс. гелеобразование происходит почти мгновенно, менее $2 \%$ масс. - составляет несколько суток, а гель получается непрочным. Поэтому учитывая возможность регулирования времени гелеобразования и прочностных характеристик созданного гелевого каркаса появляется возможность задавать время гелеобразования для конкретных термобарических условий пластовой среды. 


\begin{tabular}{l} 
Bремя, час \\
175 \\
\hline 150 \\
\hline 125 \\
\hline 100 \\
\hline 75 \\
\hline 50 \\
\hline 25 \\
\hline 0 \\
\hline
\end{tabular}

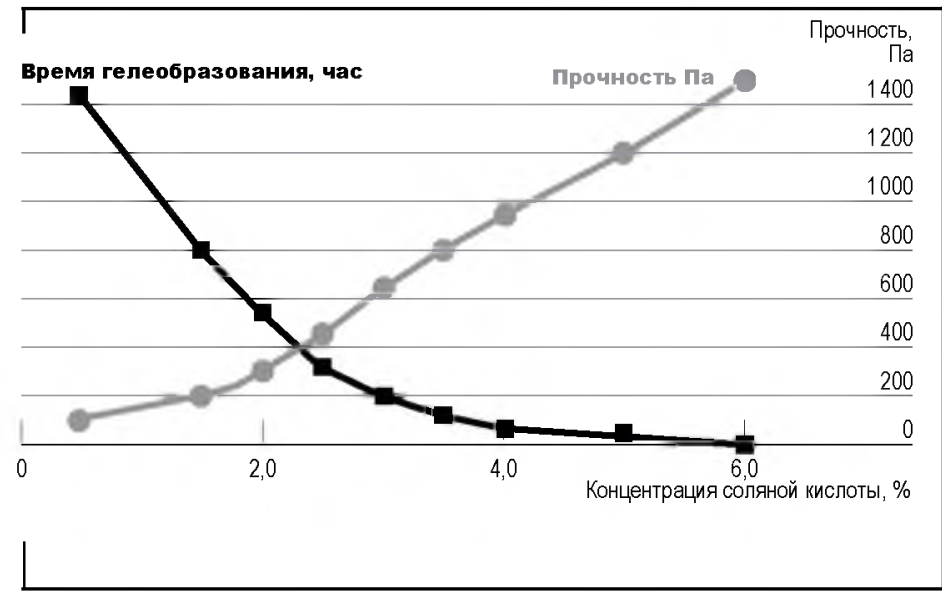

Рис. 4.

Зависимость времени гелеобразования и прочности геля от концентрации соляной кислоты (10\% раствор реагента КОМ-C) при $20^{\circ} \mathrm{C}$.

Pic. 4. Gelation time and gel strength as a function of hydrochloric acid concentration (COM-C reagent $10 \%$ solution) at $20^{\circ} \mathrm{C}$

На рисунке 5 приведена зависимость времени гелеобразования и прочности геля от концентрации реагента КОМ-С в гелеобразующем составе при температуре $20^{\circ} \mathrm{C}$. В исследуемом интервале концентраций реагента КОМ-С оптимальное время гелеобразования и прочность отмечается при конщентрации реагента 7\% масс. Кроме того, тестируемые гелеобразующие композиции на основе КОМ-С устойчивы к размыву пресной водой. Однако разрушение геля происходит при воздействии на них $15 \%$ раствором щелочи до прозрачного раствора, практически непосредственно в процессе перемешивания.

\begin{tabular}{l} 
Bpem, чac \\
24 \\
\hline 20 \\
\hline 16 \\
\hline 12 \\
\hline 8 \\
\hline 4 \\
\hline 0
\end{tabular}

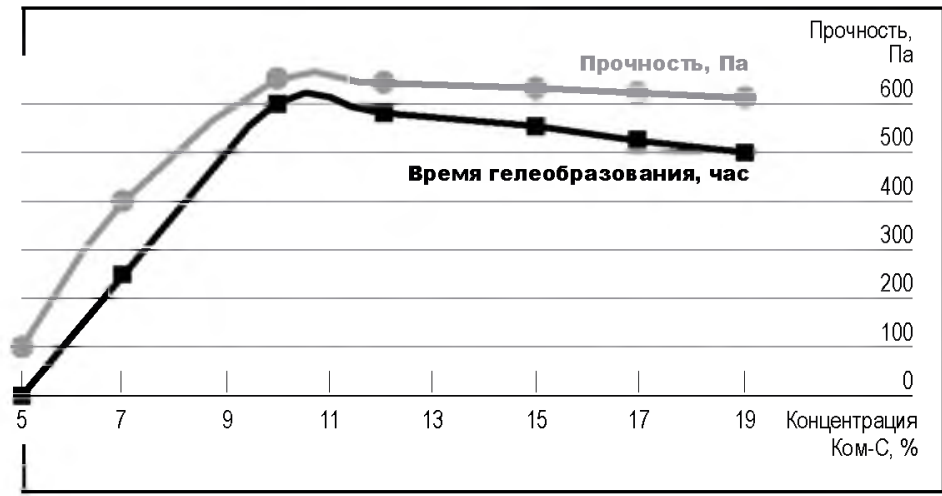

Рис. 5.

Зависимость времени гелеобразования и прочности геля от концентрации реагента КОМ-С (3\% раствор соляной кислоты) при $20^{\circ} \mathrm{C}$.

Pic. 5. Gelation time and gel strength as a function of COM-C reagent concentration (hydrochloric acid $3 \%$ solution) at $20^{\circ} \mathrm{C}$. 
Для регулирования времени гелеобразования предложены соединения, образующие с соляной кислотой устойчивые гидрохлоридные комплексы. Предполагается, что в рассматриваемом случае равновесная концентрация соляной кислоты в композиции будет меньше, чем её расчетное значение. В итоге процесс гелеобразования замедляется при условии, когда расход соляной кислоты при взаимодействии с жидким стеклом компенсируется смещением равновесия комплексообразования.

Необходимыми свойствами, связанными с замедлением химической реакции гелеобразования обладают азотсодержащие соединения. Особый интерес в данном случае представляет использование карбамида, являющегося многотоннажным и относительно дешевым реагентом. Применение последнего в нефтедобыче при проведении ремонтно-изоляционных работ в качестве компонента гелеобразующей системы широко известен. Например, при получении термотропных гелей в композиции с солями алюминия карбамид применяется несколько десятилетий. При высоких температурах в нефтяной залежи происходит гидролиз карбамида с образованием аммиака и двуокиси углерода. Из-за выделения аммиака происходит увеличение показателя $\mathrm{pH}$ воды и как следствие образование высоковязких гелей гидроксида алюминия, блокирующих высокопроницаемые пропластки.

В лабораторных экспериментах установлен факт значительного ускорения процесса гелеобразования в композиции с реагентами КОМ-С и соляной кислотой. Практически через 2 часа рассматриваемая композиция становится нетекучей гидрогелевой системой. Дальнейшее разбавление композиции с карбамидом не повлияло на увеличение времени гелеобразования. Механизм процесса гелеобразования уточняется. В таблице 2 представлены результаты рентгено-флуоресцентного анализа синтезированного реагента Ком-С и его прототипа.

Таблица 2. СОДЕРЖАНИЕ ЭЛЕМЕНТОВ В ПЕРЕСЧЕТЕ НА ОКСИДЫ МЕТОДОМ РЕНТГЕНО-ФЛУОРЕСЦЕНТНОГО АНАЛИЗА

Table 2. Content of elements in terms of oxides by the method of x-ray fluorescence analysis

\begin{tabular}{l|ll}
\hline Соединение & $\begin{array}{ll}\text { Содержание в образце, \% } \\
\text { Гипан/СH }\end{array}$ & Ком-С \\
\hline 25,268 & 31,055 \\
\hline $\mathrm{SiO}_{2}$ & 10,767 & 16,778 \\
\hline $\mathrm{Na}_{2} \mathrm{O}$ & 0,590 & 0,670 \\
\hline $\mathrm{Al}_{2} \mathrm{O}_{3}$ & - \\
\hline $\mathrm{CaO}$ & 0,057 & 0,241 \\
\hline $\mathrm{SO}_{3}$ & 0,046 & 0,006 \\
\hline $\mathrm{Fe}_{2} \mathrm{O}_{3}$ & 0,038 & 0,018 \\
\hline $\mathrm{K}_{2} \mathrm{O}$ & 0,012 & 51,119 \\
\hline $\mathrm{CO}_{2}$ & 63,223 &
\end{tabular}


В ходе выполненного исследования были получены следующие результаты. Содержание соединений кремния в составе КОМ-С, составляющее $31,1 \%$, выше, чем в составе ГИЖ. Кроме того, содержание солей натрия также выше - 16,8\%, по сравнению с ГИЖ - 10,8\%. По-видимому, элементы $\mathrm{Al}$, $\mathrm{Fe}, \mathrm{Ca}, \mathrm{K}, \mathrm{S}$ - это следы нерастворимых алюмосиликатов из $\mathrm{CH}$. Соотношение $\mathrm{Si}_{2} \mathrm{O}$ (неорганическая часть) к $\mathrm{CO}_{2}$ (органическая часть) составляет 0,6 , что характеризует способность полимера удерживать полисиликат натрия. Следовательно, можно предположить, что в реагенте КОМ-С содержание кремния больше, чем в его прототипе.

Гидролизованная макромолекула ПАН способствует образованию макроструктуры силикатного геля за счет ионных связей и определяет кислотноосновное равновесие в системе ПАН-силикат натрия. Гидролиз происходит в случае вывода иона $\mathrm{OH}$ из реакционной системы с образованием геля поликремниевой кислоты, имеющего трехмерную структуру. Причем макроструктура геля силиката натрия зависит от количества воды, $\mathrm{pH}$ и примесей ионов поливалентных металлов и формируется из первичных глобул посредством димеров с образованием силоксановых связей [7]. В щелочном геле часть димеров выполняют роль связующих мостиков между глобулами, оставшаяся часть димеров располагается на поверхности глобул, находясь внутри пор геля. На рисунке 6 представлен фрагмент макромодели щелочного силикатного геля.

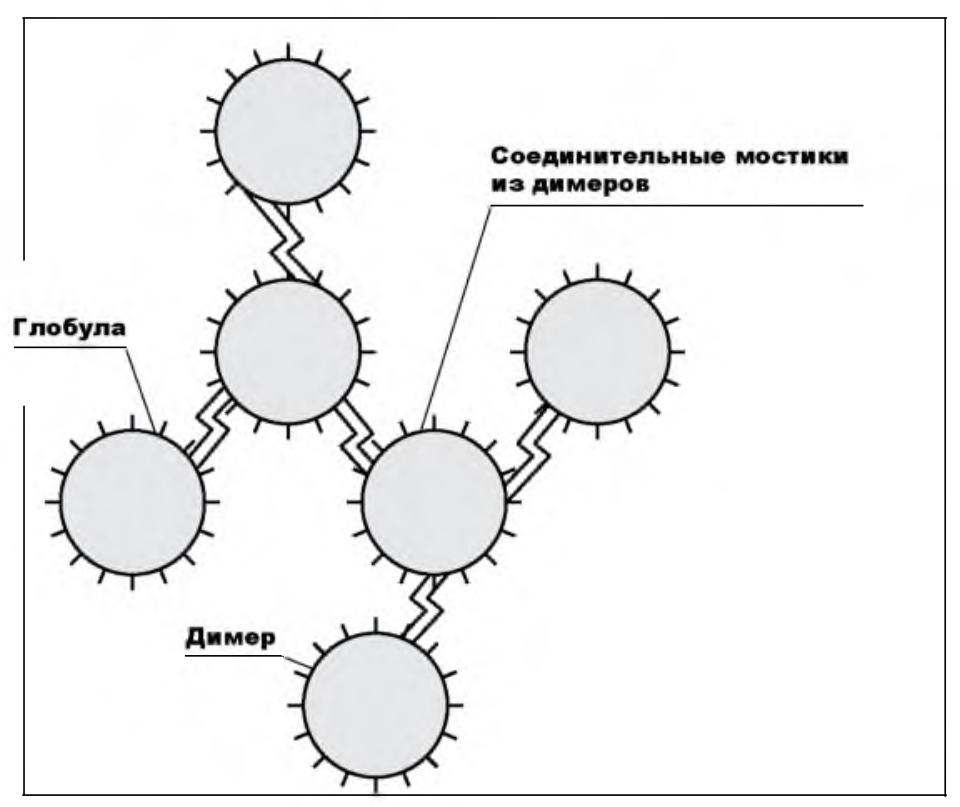

Рис. 6.

Фрагмент макромодели щелочного силикатного геля (двумерное изображение).

Pic. 6. Fragment of macromodel alkaline silicate gel (two-dimensional image). 
Димеры, расположенные на поверхности глобул и выполняющие функции мостиков, содержат до четырех катионов натрия, а на поверхности глобул - до пяти. В водной среде катионы натрия могут быть замещены слабокислотными катионами $\mathrm{Si}-\mathrm{O}-\mathrm{H}$ группами.

Основным условием гелеобразования силикатного геля при $\mathrm{pH}>7$ является наличие кислотно-основной пары и ионов ОН щелочной среды. Преобладание ионов $\mathrm{OH}$ влияет на процесс формирования гидрогеля с коротким временем образования. При воздействии кислот на СН, протоны, содержащиеся в системе, выполняют функции обменных катионов в отношении СН при его переходе в кремниевую кислоту. Невысокие прочностные характеристики макроструктуры щелочных гелей связаны с малым количеством точек контакта между глобулами. Гель, образованный при $\mathrm{pH}>7$ отличается большим размером глобул, малой удельной поверхностью и большим объемом пор [8].

Гидролизованный полиакрилонитрил представлен полианионным полимером, в котором отрицательный заряд функциональных групп компенсируется ионами натрия. При снижении $\mathrm{pH}$ композиции с $\mathrm{CH}$ происходит замещение ионов натрия на положительно заряженные функциональные группы глобул $\mathrm{Si}-\mathrm{O}-\mathrm{H}^{+}$, способствующее формированию структурных связей между молекулами полимера, обеспечивающих образование прочного и эластично-упругого геля. На рисунке 7 приведена макромодель геля силикат-гидролизованный ПАН.

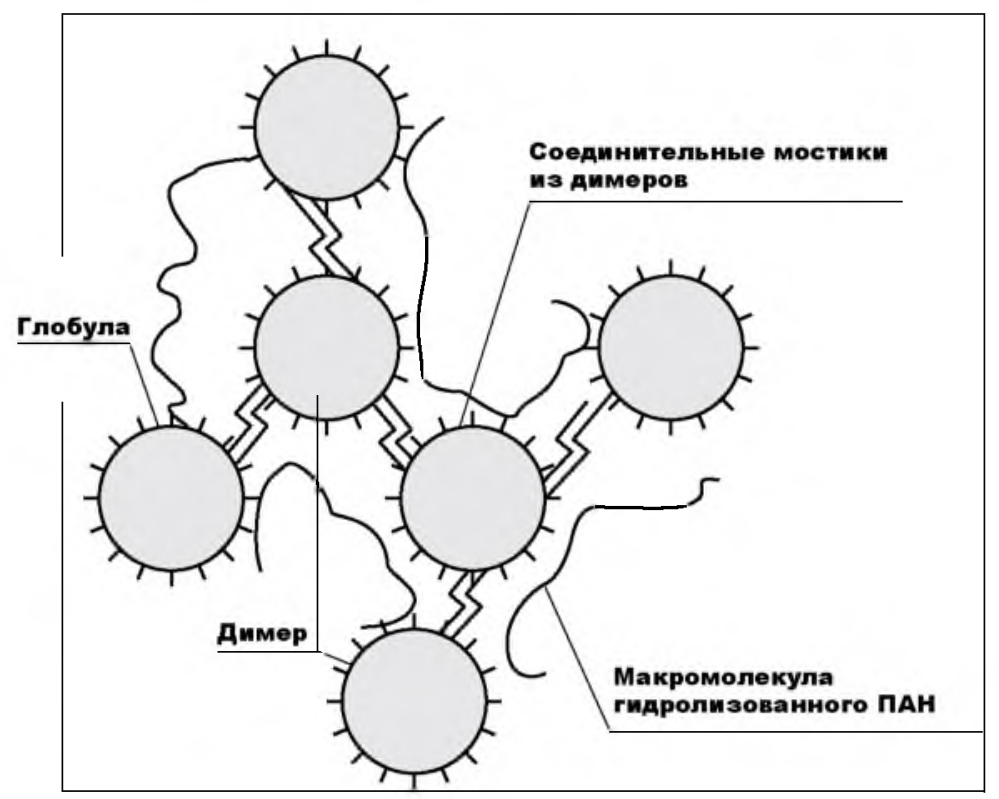

Pис. 7.

Макромодель геля силикат-гидролизованный ПАН.

Pic. 7. Macromodel gel silicate-hydrolyzed PAN. 
Согласно данной схематизации результатом замещения является образование прочного и одновременно эластично-упругого геля.

Реологические свойства рассматриваемого геля характеризуют более высокую прочность по отношению к силикатному гелю при одинаковых значениях $\mathrm{pH}$, проявляя вязко-упругие и вязко-пластичные свойства. Гидролизованный силикатом натрия ПАН представляет собой комплексную структуру, армированную полимерными волокнами, тем самым обеспечивая высокие прочностные характеристики геля. В общем виде структура интегрирования силикатных глобул в ПАН может быть представлена на рисунках 8 и 9.

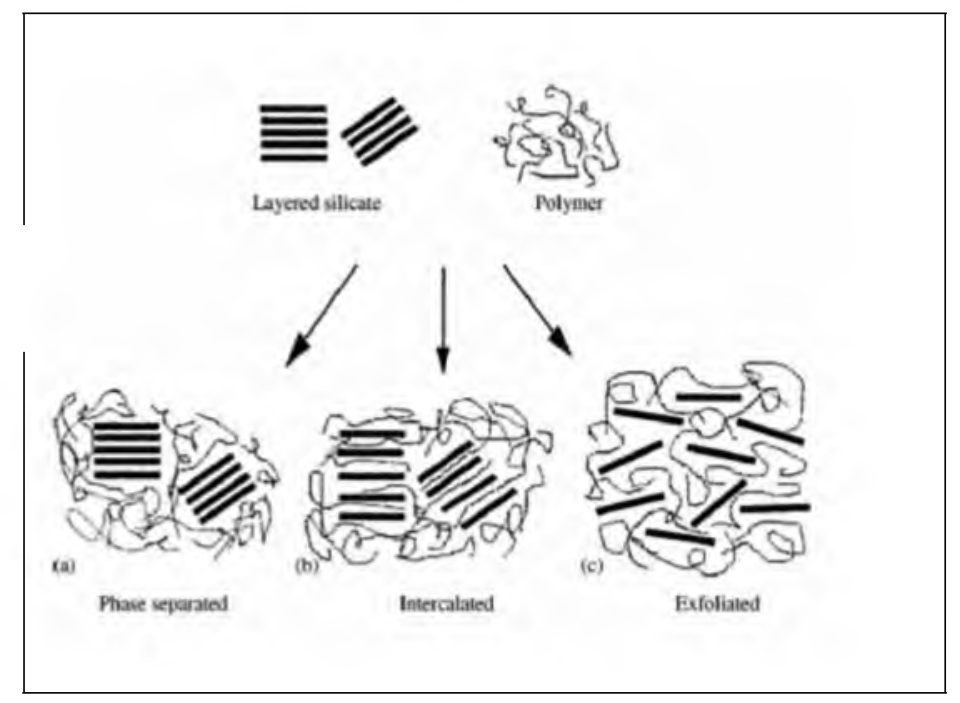

Рис. 8.

Вероятные полимер/силикатные структуры [9].

Pic. 8. Probable polymer/ silicate structures [9].

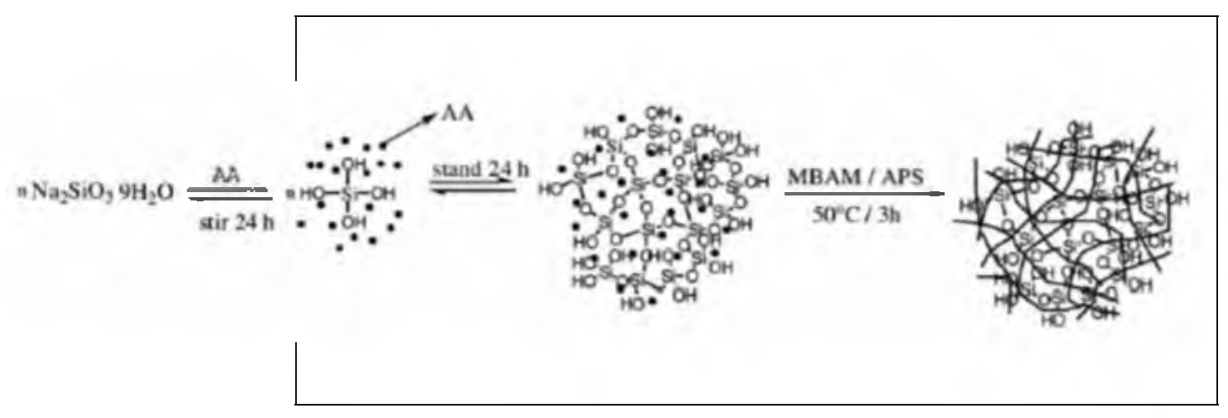

Рис. 9.

Предполагаемый процесс образования геля силиката с полиакрилатом со структурой «ядро-оболочка» [10].

Pic. 9. The proposed process of the silicate gel with a polyacrylate formation with a core-shell structure [10]. 


\section{Выводы}

1. Обоснован новый процесс гидролиза полиакрилнитрила, в котором использован силикат натрия с оптимальным соотношением 1:15 с образованием сополимера акриламида, акриловой кислоты и звеньев имидоэфира кремниевой кислоты. При условии, что макроструктура нового силикатного геля образовывается за счет ионных взаимодействий.

2. Подтверждено наличие кремния, с содержанием $31 \%$, в реагенте КОМ-С, образующего гидрогели при реакции с раствором соляной кислоты.

3. Реологические исследования ГОС на основе реагента КОМС установили его высокие прочностные характеристики за счет дополнительного армирования полимерными волокнами, вязко-упругие свойства и устойчивость к процессам разбавления водой по сравнению с прототипом - реагентом ГИЖ.

Работа выполнена при финансовой поддержке РФФИ, проект 18-29-24086 мк.

\section{Библиографический список}

1. Рогачев М.К., Ленченков Н.С., Петров Д.А., Ленченкова Л.Е., Акчурин Х.И. Обоснование применения в карбонатных коллекторах потокоотклоняющих технологий на основе кислотных гелеобразующих составов // Нефтяное хозяйство, 2012, № 8. C. $129-131$.

2. Колесов С.В., Глухов Е.А., Чезлова А.В., Козлова А.С., Чезлова А.А. Получение реагента на основе отходов полиакрилонитрила для нефтеотдачи // Химические реактивы, реагенты и процессы малотоннажной химии: Материалы XXX Международной научно-технической конференции, посвященной памяти академика Академии наук Республики Башкортостан Дилюса Лутфуллича Рахманкулова. Уфа: Изд-во Реактив, 2014. С. 217-218.

3. Ленченкова Л.Е., Акчурин Х.И., Гумерова А.С., Волошин А.И. Новый состав для блокирования обводненных зон пласта полисиликатными гелеобразующими составами // IV Международная (XII Всероссийская) научно-практическая конференция «Нефтепромысловая химия»: Материалы IV Международной научно-практической конференции «Нефтепромысловая химия». Москва: Изд-во РГУ нефти и газа имени И.М. Губкина, 2017. C. $19-22$ 
4. Якубов Р.Н., Козлова А.С., Ленченкова Л.Е. Прогнозирование эффективности применения технологии ограничения водопритоков с применением гидродинамического моделирования // Наукоемкие технологии в решении проблем нефтегазового комплекса в год экологии в России: Материалы VII Международной научной конференции. Уфа: Изд-во БГУ, 2017. С. 56-57.

5. L. T. Pham, D. G. Hatzignatiou. Rheological evaluation of a sodium silicate gel system for water management in mature, naturally-fractured oiffields // Journal of Petroleum Science and Engineering, Volume 138, 2016. Pp. 218-233

6. Dai C., Zhao F. Profile Control and Water Shutoff. In: Oilfield Chemistry. Springer, Singapore, 2018

7. Айлер Р Химия кремнезема. М.: Мир, 1982.

8. Нигматуллин Э.Н., Акчурин Х.И., Ленченкова Л.Е. Обоснование механизма гелеобразования в растворах полисиликатов натрия при действии кислот // Электронный научный журнал Нефтегазовое дело. 2012. № 3. С. 375-383.

9. Alexandre $\mathrm{M}$, Dubois $\mathrm{P}$. Polymer-layered silicate nanocomposites: preparation, properties and uses of a new class of materials // Mater Sci Eng. 2000.28. Pp. 1-63

10. Xiaomei Shi, Shimei Xu, Jiantao Lin, Shun Feng, Jide Wang Synthesis of SiO2-polyacrylic acid hybrid hydrogel with high mechanical properties and salt tolerance using sodium silicate precursor through sol-gel process // Materials Letters. 2009. 63. pp. 527-529

\section{References}

1. Rogachev M.K., Lenchenkov N.S., Petrov D.A., Lenchenkova L.E., Akchurin Kh.I. Justification of implementation of water control technology by using acid gel compounds in carbonate rocks. Oil Industry. 2012. No. 8. pp. 129-131.

2. Kolesov S.V., Glukhov E.A., Chezlova A.V., Kozlova A.S., Chezlova A.A. Obtaining a reagent based on polyacrylonitrile waste for oil recovery // Proceedings of XXX International Scientific and Technical Conference "Chemical reagents, reagents and processes of low-tonnage chemistry". Ufa: Reaktiv Publ. 2014. pp.217-218.

3. Lenchenkova L.E., Akchurin Kh.I., Gumerova A.S., Voloshin A.I. New composition for blocking watered areas of the reservoir with polysilicate gel-forming compounds // Proceedings of IV International Scientific and Technical Conference "Oilfield chemistry". Moscow: Gubkin Russian state university of oil and gas Publ. 2017. pp. $19-22$

4. Yakubov R.N., Gumerova A.S., Lenchenkova L.E. Forecasting water shut-off treatment efficiency with the application of hydrodynamic modeling. Proceedings of VII International Scientific Conference «High technology in solving problems of the oil and gas complex in the year of ecology in Russia». Ufa, BashGU Publ. 2017. pp.56-57. 
5. L. T. Pham, D. G. Hatzignatiou. Rheological evaluation of a sodium silicate gel system for water management in mature, naturally-fractured oilfields // Journal of Petroleum Science and Engineering, Volume 138. 2016. pp. 218-233

6. Dai C., Zhao F. Profile Control and Water Shutoff. In: Oilfield Chemistry. Springer, Singapore. 2018

7. Ailer R. The chemistry of silica. M.: Mir. 1982.

8. Nigmatullin E.N., Akchurin Kh.I., Lenchenkova L.E. The explanation mechanism of gelation in sodiumpolysilicate solutions with acids effect study. Electronic Scientific Journal "Oil and Gas Business», 2012. No. 3. pp. 375-383.

9. Alexandre $\mathrm{M}$, Dubois P. Polymer-layered silicate nanocomposites: preparation, properties and uses of a new class of materials // Mater Sci Eng. 2000.28. pp.1-63

10. Xiaomei Shi, Shimei Xu, Jiantao Lin, Shun Feng, Jide Wang Synthesis of SiO2-polyacrylic acid hybrid hydrogel with high mechanical properties and salt tolerance using sodium silicate precursor through sol-gel process // Materials Letters. 2009. 63. pp.527-529

Рукопись поступила в редакции: 18.04.2019. Принята к публикации: 01.06.2019

\section{O6 авторах}

Гумерова Александра Сергеевна, инженер ООО Научно-производственный центр "Комплекс-Ойл", Российская Федерация, 450064, г. Уфра, ул. Мира, д.14, e-mail: sasha04@list.ru

Якубов Равиль Наилевич, кандидат технических наук, доцент кафедры «Разработка и эксплуатация нефтяных и газонефтяных месторождений» Уфримского государственного нестянного технического университета, Российская Федерация, 450062, г. Уфа, ул. Космонавтов, 1, тел. (347) 243-17-71, e-mail: rnyakubov@gmail. com, SCOPUS ID: 55538101600.

Ленченкова Любовь Евгеньевна, доктор технических наук, профессор кафредры «Разработка и эксплуатация нефттных и газонефртяных месторождений» Уфимского государственного нефтяного технического университета, Российская Федерация, 450062, г. Уфа, ул. Космонавтов, 1, тел. (347) 243-17-71, e-mail: lenchenkoval@ mail.ru, SCOPUS ID: 55531591400.

Илаш Дмитрий Александрович, аспирант, преподаватель кафедры «Разработка и эксплуатация нефтяных и газонефтяных месторождений» Уфимского государственного нефтяного технического университета, Российская Федерация, 450062, г. Уфа, ул. Космонавтов, 1, тел. (347) 243-17-71, e-mail: raideril@yandex.ru 


\section{About the authors}

Gumerova Aleksandra S., engineer LLC Research and production center "Complex-Oil", 14, Mira str., Ufa, 450064, Russian Federation, e-mail: sasha04@list.ru.

Yakubov Ravil N., Candidate of Technical Sciences, Assistant Professor of Oil and Gas\&Oil Fields Development and Operation Department Ufa State Petroleum Technological University, 1, Kosmonavtov str., Ufa, 450062, Russian Federation, tel.: (347) 243-17-71, e-mail: rnyakubov@gmail.com, SCOPUS ID: 55538101600

Lenchenkova Lyubov E., Doctor of Technical Sciences, Professor of Oil and Gas\&Oil Fields Development and Operation Department Ufa State Petroleum Technological University, 1, Kosmonavtov str., Ufa, 450062, Russian Federation,

tel.: (347) 243-17-71,

e-mail: lenchenkoval@mail.ru, SCOPUS ID: 55531591400.

Ilash Dmitrii A., Post-gradient student, Lecturer of Oil and Gas\&Oil Fields Development and Operation Department Ufa State Petroleum Technological University, 1, Kosmonavtov str., Ufa, 450062, Russian Federation,

tel.: (347) 243-17-71,

e-mail: raideril@yandex.ru. 